\title{
The Development of an Effective Management Model of Professional Education as a Factor of Increasing the Regional Economy Competitiveness
}

\author{
Inna Vladimirovna Igolnikova
}

Irina Alekseevna Matyushkina

\author{
Ludmila Sergeyevna Mityuchenko
}

Olga Mikhailovna Mikhalyova

Elena Mikhailovna Shadoba

Bryansk State University named after Academician I.G. Petrovsky

Doi:10.5901/mjss.2015.v6n5s3p291

\begin{abstract}
Major factors of competitiveness of national and regional economies increased on the basis of ensuring close interrelation of economy and system of professional education in Russia are considered in the article. One of the direction of the analysis is studying of features of various foreign models of professional education management, detection of their features, merits and demerits. The main directions of modernization of the Russian social economic process, on the basis of introduction of bioadequate model in a control system of professional education in Russia are offered in the article. According to authors, elements of management that will allow to create optimum model which will accurately distribute and coordinate functions and powers, competences and responsibility of various subjects and objects of management of system of professional education, first of all professional educational institutions and local governments, and also regional and federal administrative structures have to be allocated.
\end{abstract}

Keywords: models of management of education, professional education.

\section{Introduction}

The control system of professional education is at a stage of serious organizational and economic and administrative transformations. In the conditions of changing demographic situation in the country, formation of the new economic and organizational relations, search of effective mechanisms of management of professional education on the basis of use of potential of regional development is of particular importance.

Need of coordination of labor market inquiries and system of professional education demands from all governing bodies of professional education system using of new administrative methods for achievement of the greatest possible economic and social results. So, new approaches to management of professional education in regions demand further studying; possibilities of use of capacity of strategic management for formation of the new mechanism of its development, feature of interaction of labor market and educational institutions at the regional level.

Rationalization of interaction of federal, regional and municipal control systems of professional education will allow to balance the resource capacity of educational institutions and economic, social results of their activity that will allow to counteract, in turn, influence of negative factors of the external and internal environment.

Besides, you shouldn't forget that for a sustainable development of economic system it is necessary to increase efficiency of realization of production, personnel, natural and resource potentials and to define a vector of development of systems national and regional labor markets, the capital, innovations, goods. Thus productivity and efficiency of economic system are a basis for creation of quality conditions and a standard of living of the population, sustainable social and economic development, and also improvement of production and marketing infrastructure of the region. Analyzing a current state and dynamics of the Russian economy and generalizing tendencies of its development, it is possible to reveal and formulate major factors which will be directed on activization of internal opportunities and competitive advantages of economic development of Russia:

- the high level of education of the population and the created system of spiritual traditions and values focusing 
Russians on realization of creative abilities, establishment of social partnership and aspiration to social justice;

- the advanced research and personnel potential, own schools of sciences which are carrying out the advanced development in a number of the directions of the latest technological way;

- the impressive sizes of free capacities in the knowledge-intensive industry which can become a platform for a new stage of economic development;

- providing the main part of needs of domestic producers for raw materials, resources and energy carriers on the basis of own natural resources;

- the big territory and various domestic market providing realization of opportunities of satisfaction of public requirements.

Thus, despite considerable problems for the Russian economy there is powerful research and production potential and there are necessary resources for further modernization.

One of the main conditions providing effective modernization of the Russian economy is providing all branches and spheres with necessary personnel potential. Realization of this condition is closely connected with improvement of a control system of professional education which demands development of new Russian model of interrelation of the state interests and interests of society represented by various institutes and the population.

\section{Research Theory and Methods}

Research objective is the analysis Russian and foreign models of management of system of professional education and development of a new control system of the higher education in Russia on the basis of bioadequate model taking into account experience of management of foreign countries.

Methodological basis of research are the dialectic principles of interrelation of the subject and object, process and result, single, special and the general, unity of tradition and an innovation. Carrying out research the complex of complementary methods is used for achievement of a goal:

- general-theoretical methods of knowledge (analysis, synthesis, analogy, comparison, comparison, generalization, classification, systematization, abstraction, interpretation, analysis and synthesis of scientific references, documents and practical experience, etc.);

- experimental methods of research (analysis of normative and information documents, results and expert descriptions of administrative activity).

\section{Results and Discussion}

As a result of synthesis of experience of management of professional education abroad, it was revealed that from a position of studying and definition of positive experience of management of professional education control systems of such countries as Germany, France and Denmark are the most interesting.

The German model of professional education is a dual system. It is based on a firm binding of system of a vocational education to the enterprise. The list of the educational programs realized within a dual system is defined proceeding from requirements of economy, and is formed in close cooperation between federation, lands and social partners. According to official data the trajectory and the maintenance of an educational program are guided by requirements imposed in a consequence to the potential employee on a workplace. Dual education in Germany, in fact, is a state program, which has the budgetary financing, but on a parity basis with the enterprises. Training of specialists at a dual education system is realized by means of parallel training at the enterprise and at vocational school. The vocational education at the enterprise is controlled and regulated from federal governing bodies, and training at vocational schools belongs to a subject of introduction of certain territories (lands). They represent regional educational institutes of system of the general and professional education. A main objective of realization of vocational school is training addition directly at the enterprise with special theoretical knowledge (two thirds of time) and increase of general education level of the trainee (one third of time). At vocational training visit of such professional school obligatory that is fixed by the relevant territorial laws. Obtaining practical skills directly at the enterprise is carried out either in educational workshops or on a workplace at the large enterprises, or only on a workplace at the small enterprises. Also one of participants of the created system are interproduction training centers. Their same function, as at the enterprises, is training in practical skills. Most often such centers accept to themselves on training of future experts in case the enterprise has very narrowly targeted specialization and can't provide the pupil with the corresponding workplace. Besides, separate grade levels can pass and at other enterprises of the earth (Toropov D.A., 2005).

Example of rigidly adjustable control system of professional education attached to educational institution is the 
system of vocational education of France. In France, as well as in Russia, there is rather rigid centralized control system of professional education so far. Now the French system of a vocational education is one of factors of growth of labor productivity and economic development. In this regard investments into this sphere have priority character and are supported from the state. Thus decentralization of management of educational institutions can be considered as the main tendency of development. For administrations of regions and municipalities the rights for activity in the field of the organization of different types of preparation, the organization and carrying out certification of teaching staff are transferred.

Processes of decentralization of management take place in educational system of France with expansion of a field of independent decision-making for the state educational institutions of professional education. So, the Board of trustees of educational institution can legitimately limit powers of the director of the educational institution appointed by the state. Also educational institutions acquired the right more freely to dispose of the received means, having thus opportunity in addition them to earn and to spend at discretion.

Management of professional education in Denmark is based on the combination of duality and statehood. Denmark is the country of almost general literacy. However the main administrative powers and functions in an education system are under authority of government bodies of management. The general principles of education are also established by the state. In the majority averages and higher educational institutions are state. They are subordinated to the Ministry of Education or the Ministry of Culture. The higher academic education is presented by universities. The highest unacademic education is provided by the highest institutes realizing educational programs of university level in area on architecture, music, economy, engineering, etc. and also the higher educational institutions of unacademic type which are carrying out preparation on the specialties which aren't relating to the category academic - journalism, pedagogy, sociology. It is possible to get the continued education in Denmark in the university centers realizing one or two-year courses of basic preparation and prehigh school orientation (similarly Russian training courses and preparatory offices). "Open education" represents education for adults, the working people needing change of a profession or professional development. Open education is only paid (from 400 to 800 kroner for one semester) and it consists in studying of separate specialized disciplines. Results of intermediate, total and qualification tests (examinations) in sector of "open education" are equated to examination results of universities programs.

According to the Russian model of professional education it should be noted that fundamental bases of this model were created during the Soviet period. Formation of system of the advancing training according to which education was based taking into account requirements of regional production in the near future became her main progressive idea. Development of the system of criteria of quality of professional education and involvement of bodies of professional education at the level of the region to process of development of curricula became the second idea. All this created certain prerequisites to formation of professional education as uniform complete system. However, during the considered period, also the factors constraining development of professional education were defined. They are: rigid centralization and directive methods of management, total advance planning and control of activity of educational institutions, educational ideologization, educational orientation not on development of the identity of future professional, and, first of all, on preparation of the qualified mass labor with orientation to a priority of inservice training. From our point of view, it is necessary to consider developed, and already socially and economically adapted, effective principles of development and functioning of system of professional education in the past for formation of model of quality professional education.

The Russian model of management of professional education since 2000 undergoes a number of fundamental changes. In the country within a strategic orientation of a state policy in the field of education modernization of Russian education was officially approved. According to "The concept of modernization of Russian education for the period till 2010" it was necessary to provide conditions for improvement of quality of professional education of all existing levels. As the main actions development of rational model of realization of secondary education at observance of a condition of interrelation of the existing professional educational programs and ensuring vertical mobility of the trained is allocated. But realization in practice of the put plans faced a number of vital issues. In the sphere of secondary education the principal are: insufficient financing of educational institutions, absence of real interrelation of educational institutions with employers, lack of the modern mechanism of monitoring of requirements of labor market and territorial distribution of young specialists, for staffing all of branch sectors of economy. Considering system of the higher education, it should be noted that process of modernization of system of professional education calls higher educational institutions, to join in integration of various fields of activity: educational, scientific and innovative that involves need of transformation of functional and structural and institutional aspects of functioning. Generalization of modern experience of transformation of classical universities that the most effectively this process is carried out in the direction of formation of educational and scientific university complexes. Creation of university complexes means strengthening of interaction of classical university with the academic sector of science, the scientific and educational centers. Modernization of technical colleges means 
process of integration of education, science and production in educational and scientific and innovative complexes. The main feature of such complexes is association on one platform of an innovative, theoretical and production activity.

Formulating the basic principles of development of the higher education in Russia it is possible to note that the main of them are:

- close interrelation of university and academic science;

- integration of innovative production and scientific university complexes;

- participation in the international educational programs.

In general it should be noted that modernization of Russian education is carried out within realization of Bologna Process. According to which the special attention should be paid to an assessment of quality of education, thus the competence-based approach focusing the attention not so much on the general result of education has to be the basis how many in formation at the person of ability competently to work in various problem situations. According to provisions of competence-based approach, a basis of model of professional education is the professional education of the graduate which is defined how ability of the personality to carry out professional activity, based on profound fundamental knowledge, high professional competences, high basic competences (Matyushkina I.A. and Mikhaleva O.M., 2013).

Thus, leaning an assessment of the existing theories of development of professional education existing in modern science it is possible to draw the following conclusions:

- further development of professional education in the conditions of innovative society is possible only on the basis of its interaction with the economic sphere representing interests of employers. In this case the system of professional education has to be "open", and the social partnership and management of educational institution can become the main forms of interaction of education and the public; as a methodological basis of interaction of education and society the social constructivism can act;

- quality of professional education depends on compliance of level of knowledge and abilities of graduates to inquiries of modern economy; only the advancing professional education which is carrying out training of specialists taking into account tendencies of social and economic development of the certain territory or region can provide this quality;

- in the conditions of fast change of technologies, scientific progress actual is a formation of the expert of new type: possessing not so much a stable stock of knowledge, how many certain abilities and personal qualities allowing to master competently technological innovations. Therefore the competentitive approach estimating competitiveness of the identity of the graduate of professional educational institution in modern labor market becomes the new concept of professional education. A pedagogical basis of this type of education is the personal focused educational paradigm;

- transformations in research and production, information spheres quickly enough lead to updating of areas of professional knowledge therefore the system of continuous professional education is necessary for improvement of knowledge of experts or for development by the identity of new demanded specialty.

The carried-out analysis of foreign experience of management of professional education and studying of the main directions of modernization of professional education in Russia allow to reveal problems which interfere with introduction in the Russian model of management of professional education of elements of foreign control systems. Among them there are:

- absence of concrete recommendations about adaptation of the saved-up positive experience of the European systems of professional education to professional education of Russia;

- lack of uniform scientific approach to a quality problem (incompatibility of indicators and criteria of quality of educational programs in Russia and Europe).

These problems have to become a subject of adoption of the administrative decision for formation of an effective control system of professional education and, first of all, especially within higher educational institutions. Only such approach will allow to provide effective achievement of the objectives, the educational services facing all participants of the market. To the solution of an objective in the theoretical plan there corresponds the model of social and economic process offered by professor N. M. Gorbov (Gorbov N.M. and Gorbova T.M., 2004). The offered concept of social and economic process is the basis for our methodological approach to consideration of management of system of professional education (Shadoba E.M, 2014).

The bioadequate model of management of system of professional education is presented in figure 1.

It is established that process of management of professional education is defined by system of the interconnected primary elements (spheres) (Mikhaleva O.M., 2009):

1. Requirements of society and citizens in professional education (the sphere of requirements).

2. Personnel potential of professional education is an object of management in system of professional education 
(the professional sphere).

3. Material and information base (technical sphere).

4. Students are an object of management in system of professional education (the subject sphere).

5. Pedagogical technologies (technological sphere).

6. The graduate is an object of management in system of professional education (the productive sphere).

7. Subjects of management of system of professional education who include: The Ministry of Education and Science of the Russian Federation, others state (federal and regional) both municipal governing bodies of education and public structures which have opportunity to make decisions in the sphere of management of system of professional education.

8. Establishment of rational interrelations and interaction of subjects and objects of management of system of professional education.

9. Factors of the external and internal environment.

The developed model subjects of management of system of professional education are presented in the center.

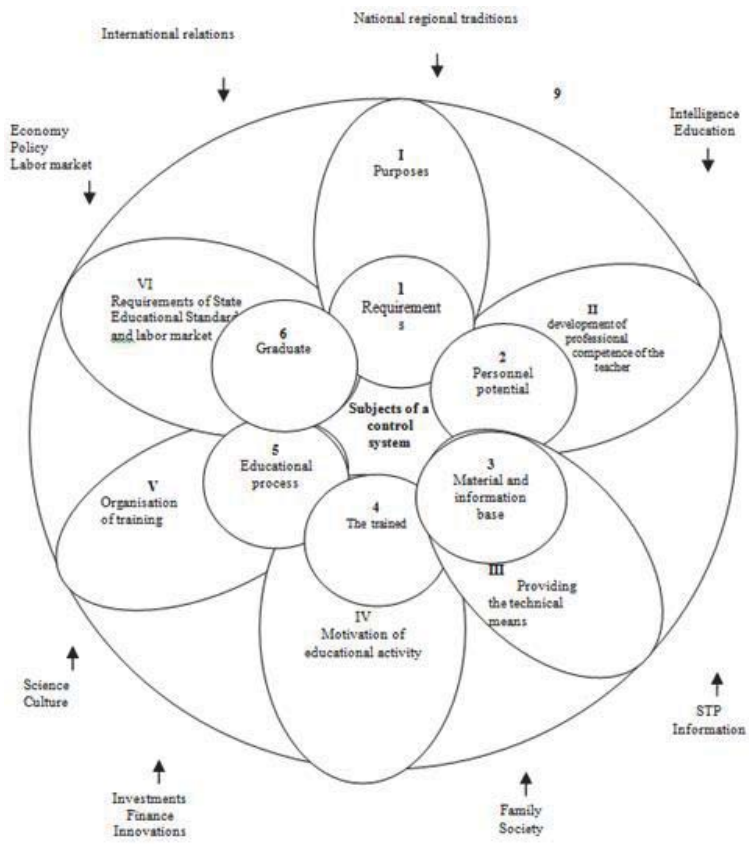

Figure 1 - Bioadequate model of management of system of professional education: federal and regional components

The developed primary elements will allow to create optimum model of management which will accurately distribute and coordinate functions and powers, competences and responsibility of various subjects and objects of management of system of professional education, first of all professional educational institutions and local governments, and also regional and federal administrative structures.

As the main specific feature of this model mutual penetration of all elements 1-7 acts: each separate element of interrelation provides mutually penetrability with the subsequent and the previous elements (Gorbov N. M. and Shadoba E. M., 2012). In this regard we suggest to allocate and prove the following combinations of the main central social element 7 to elements 1-6 and I-VI which form the most various systems:

Social marked system (7-1-I). Management process in system of professional education arises from the moment of emergence of requirement of society and citizens in professional education and is defined by the purposes of State Educational Standard and inquiries of labor market.

Social professional system (7-2-II) is defined by extent of development of professional competence of teachers which reflects and proves quantitative expenses of energy of the mind necessary for satisfaction of requirements. In turn, 
for formation of competence of the teacher it is necessary to consider possibility of a rational combination of different types of activity (teaching and educational, educational and methodical, organizational and administrative and research) which are regulated and regulated by administration of the relevant educational institution.

Social technical system (7-3-III) is defined by a level of development of material and information base. Resources of internal development of the teacher are caused by familiarity degree in educational process of material and information tutorials. That is, if in educational process there is an underexploitation of any resources, for example, intellectual opportunities of the teacher or material means, it can be caused by a mismatch of professionalism of the teacher and a level of development of material base.

Social subject system (7-4-IV) is defined by extent of development trained which are active consumers of educational services. In this system the main factor which will allow to create high creative activity and working capacity trained, need and possibility of improvement of system of educational motivation of pedagogical activity will act.

Social technological system $(7-5-\mathrm{V})$ is characterized by efficiency of the organization of educational process. Everybody know that the main element of educational process are pedagogical technologies which demand creation of comfortable conditions for introduction, development and development of new interactive author's educational technologies.

Social effective system $(7-6-\mathrm{VI})$ is defined by extent of training of the graduate. In modern society the main tool defining requirements to the level of competence and formation of the graduate, and also the requirement to further professional activity are State Educational Standard and inquiries of regional labor markets. The mechanism of interaction of these tools allows to carry out an objective assessment not only the end results of educational process, but also to trace its dynamics on the basis of continuous monitoring. In turn the received results act as the basis for correction of the educational purposes and tasks.

The organizational sphere (8) assumes the organization of rational work on interaction of subjects and objects of management of the system of professional education directed on creation of conditions which will allow to organize effective functioning and improvement of system of professional education for the all-round development of the personality which is trained, in interests of the person, society, state.

Environment (9). Any social and economic process proceeds in the environment having on it impact. In this regard improvement of the mechanism of interaction of system of professional education and environment is required (Shadoba E.M., 2014).

The offered bioadequate model of management of system of professional education considering non-uniform, interrelations and the interpenetrating elements from the moment of emergence of requirements until their satisfaction, is means of increase of methodological organization of management as allows to consider federal and regional components.

On the basis of the developed bioadequate model it is possible to allocate the main directions of modernization of a control system of professional education of Russia:

1. Openness of system of professional education management, as state and public system.

This range means publicity and transparency of discussion, reasonable, objective, acceptance corresponding to modern realities, decisions in the field of management of system of professional education and control of their realization.

2. The modernization of management of system of professional education on the basis of mutually responsibility model in the sphere of professional education directed on strengthening of a role of all participants of educational policy and their rational interaction. Such model will allow to carry out accurate distribution and coordination of competences and powers, functions and responsibility of all subjects and objects of a control system of professional education: federal and regional administrative structures, local governments, educational institutions, public structures, employers, the pedagogical workers who are trained and their parents. So, each of participants of the administrative relations in system of professional education must have opportunity to influence its functioning and development, and also to bear a certain responsibility for creation of the conditions necessary for performance of professional education of the functions by system (Igolnikova I.V., 2013).

3. Improvement of the mechanism of interaction of system of professional education with environment. Thus, creation of system of relationship of education with labor markets is meant; organization of the nondepartmental monitoring system of quality of education; participation of regional authorities in a cooperation of educational institutions, etc. 


\section{Conclusion}

Improvement of management of system of professional education, both in regions, and in Russia in general, will allow to create necessary conditions for development and modernization of all social and economic system. In our opinion for ensuring development of innovative activity of economy of Russia it is necessary to form, strengthen and develop information infrastructure of research and developmental works, to create an extensive network of scientific and technical libraries, and also to keep development of experimental installations that will be successfully carried out at realization of new model of management of professional education on the basis of bioadequate model.(Mityuchenko L.S., 2012) Besides, it should be noted that the present stage of development of society and system of professional education as major social institute, are characterized by the increasing need for the competent experts having the developed creative thinking, ability to search of new ways and methods in science, economy, equipment, management. The solution of the problem of formation at the expert of the creative relation to the business is possible to use only through realization of idea of continuous education which is enabled through a self-education combination to granting opportunity at any time the help of highly skilled teachers and experts. In this regard the education model changes in general. Transition from the monomodel focused on training of the expert to multifunctional model where free development of the personality, formation of ability to self-development is on base. As one of the most real means of an embodiment of idea of continuous education in life "periodically resumed education" is offered.

Thus, modernization of management of professional education in Russia covers change of strategic development of all social and economic process which has functioning of economy in general, enterprise and state sectors, and also realization of interests of all Russians and the individual is. Improvement of the considered system needs to be carried out on the principles of social partnership of all participants of process taking into account the existing scientific provisions. Only in this case it is possible to achieve necessary rates of development of socially oriented economy which will allow the domestic organizations to make and maintain requirements of competitive fight on domestic and the world markets as, first of all, use of work of the educated, competent and successful worker is the base of efficiency of activity of any economic entity.

\section{References}

Toropov, D.A. (2005). Ensuring quality of professional education in Germany. The thesis of the doctor of pedagogical sciences, Russia. Matyushkina, I.A. and Mikhaleva O.M. (2013). The comparative analysis of development of science in Russia and abroad. Concept, ART 53482 http://e-koncept.ru/article/855/ - State registration. № ФC 77- 49965. - ISSN 2304-120X.

Gorbov, N.M. and Gorbova T.M. (2004). Modern problems of social management. In Social economy: theoretical and practical aspects of development: Collective monograph / under scientific edition of professor O.S. Sukharev, professor, honored scientist V. D. Simonenko. M.: joint stock company "Publishing house" "Economic literature". Chapter 3. pp. 1-99.

Shadoba, E.M. (2014). Structure of social and economic process of modern Russia//the New word in science: development prospects: materials of international conference.

Mikhaleva, O.M. (2009). Improvement of system of work motivation of the faculty of higher education institutions (on the example of the Bryansk region): The thesis on competition of an academic degree of Candidate of Economic Sciences. - Moscow.

Gorbov, N.M. and Shadoba E. M. (2012). Innovative approaches to development of social and economic processes. Bryansk: JSC Dizayn-Print

Igolnikova, I.V. (2013). Motivational factors of continuous professional development// Personnel officer, №5.

Mityuchenko, L.S. (2012). The use of program-target management in industrial enterprises of the Bryansk region // The strategic partnership of business and education in preparation for a practice-oriented staff: materials of interregional scientific-practical conference. 